Incidencia del Acto Legislativo 01 de 2005 en la extinción de las pensiones convencionales en el ámbito nacional y su protección por el bloque de constitucionalidad

Incidence of the legislative act 1 of 2005 in the exctinction of conventional pensions in the national domain and its protection by the block of constitutionality

Autores: Nicolas Echeverri Rodriguez, B. Nathaly Torres Torres, C. Myriam Sepúlveda López

DOI: https://doi.org/70.25058/1794600X.1054 


\title{
INCIDENCIA DEL ACTO LEGISLATIVO 01 DE 2005 EN LA EXTINCIÓN DE LAS PENSIONES CONVENCIONALES EN EL ÁMBITO NACIONAL Y SU PROTECCIÓN POR EL BLOQUE DE CONSTITUCIONALIDAD*
}

\author{
Incidence of the legislative act 1 of 2005 in the exctinction \\ of conventional pensions in the national domain and its \\ protection by the block of constitutionality
}

\author{
Impacto da Lei Legislativa 01 de 2005 sobre a extinção \\ de aposentadorias convencionais em nível nacional e sua \\ proteção pelo bloco de constitucionalidade.
}

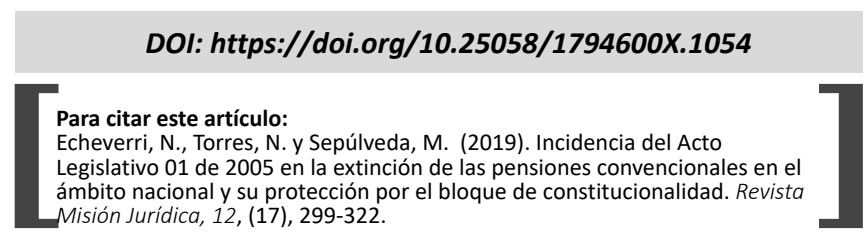

\footnotetext{
Nicolas Echeverri Rodriguez ${ }^{a}$ nechverrir@unicolmayor.edu.co B. Nathaly Torres Torres $b$ ntorrest@unicolmayor.edu.co C. Myriam Sepúlveda López ${ }^{c}$ myriam.sepulveda@unicolmayor.edu.co

Fecha de recepción: 05 de diciembre de 2017 Fecha de revisión: 27 de febrero de 2019

Fecha de aceptación: 07 de septiembre de 2019
}

\section{RESUMEN}

Por medio de un análisis jurisprudencial, enfatizando en la sentencia SU 555 de 2014, se determina el avance que ha tenido el reconocimiento de las pensiones convencionales, siendo ellas parte de la seguridad social y, de igual forma, qué incidencia ha tenido el Acto Legislativo 1 de 2005 en la extinción de estas pensiones y cuál es la protección de los Convenios de la OIT 87,98,151 y 154, junto con el Protocolo de San Salvador frente a la negociación colectiva. También se

\footnotetext{
* Artículo científico producto de investigación monográfica.

a. Abogado Universidad Colegio mayor de Cundinamarca.

b. Abogada Universidad Colegio mayor de Cundinamarca.

c. Doctora en Filosofía Jurídica de la Universidad Nacional de Educación a Distancia de Madrid, España, magister en Derecho Administrativo de la Universidad Libre, magister en Educación con énfasis en investigación de la Universidad Pedagógica Nacional de Colombia, especialista en Instituciones Jurídico Familiares de Universidad Nacional, especialista en Docencia Universitaria de la Universidad Santo Tomás, Trabajadora Social de la Universidad Colegio Mayor de Cundinamarca, Abogada de la Universidad La Gran Colombia. Decana de la facultad de derecho de la Universidad Colegio Mayor de Cundinamarca.
} 
tuvieron en cuenta la importancia del principio de sostenibilidad financiera frente a la progresión de derechos de los trabajadores.

Para ello se realizó un análisis de la evolución jurisprudencial, respecto a la regresión de derechos, expectativas legítimas, derechos adquiridos, principios generales del derecho laboral, bloque de constitucionalidad y compatibilidad de las pensiones convencionales, ahondando más en la problemática surgida a partir de la expedición de la mencionada reforma constitucional para lograr entender la falta de garantías que el Estado colombiano proporciona a sus trabajadores, excusándose en interpretaciones constitucionales que no dan cabida al desarrollo de un Estado social de derecho.

\section{PALABRAS CLAVE:}

Acto legislativo, principio de sostenibilidad, bloque de constitucionalidad, antinomia constitucional, compatibilidad de pensiones convencionales, regresión de derechos.

\section{ABSTRACT}

This scientific article is the result of an analysis carried out of judgment SU 555 of 2014 that determined the progress of the recognition of the conventional pensions, these being part of the social security of this country, it also studies the legislative act 1 of 2005 which led to the extinction of these pensions and, it considers the scope of the protection of OIT conventions $87,98,151$ and 154, together with the Protocol of San Salvador against collective bargaining. It also takes into account the importance of the principle of financial sustainability against the progress of workers' rights.

To this effect, an analysis of jurisprudential evolution, regarding the regression of rights, legitimate expectations, acquired rights, general principles of labor law, the block of constitutionality and the compatibility with conventional pensions is done, deepening on the problems arising from the issuance of the aforementioned constitutional reform to better understand the lack of guarantees that the Colombian State offers its workers, excusing themselves in constitutional interpretations that do not allow forthe development of a social State of law.

\section{KEYWORDS}

Legislative act, principle of sustainability, block of constitutionality, constitutional antinomy, compatibility of conventional pensions, regression of rights.

\section{RESUMO}

Por meio de uma análise jurisprudencial, enfatizando na sentença no 555 de 2014, determinado o progresso que levou ao reconhecimento das aposentadorias convencionais, que fazem parte da seguridade social e, da mesma forma, que impacto o ato legislativo teve $1^{\circ}$ de 2005 , sobre o término dessas aposentadorias e qual é a proteção das Convenções 87, 98,151 e 154 da OIT, juntamente com o Protocolo de San Salvador contra a negociação coletiva. Também foi levada em consideração a importância do princípio da sustentabilidade financeira contra a progressão dos direitos dos trabalhadores.

Para isso, foi realizada uma análise da evolução jurisprudencial, em relação à regressão de direitos, expectativas legítimas, direitos adquiridos, princípios gerais de direito do trabalho, bloqueio de constitucionalidade e compatibilidade de aposentadorias convencionais, aprofundando os problemas decorrentes da Emissão da reforma constitucional acima mencionada, a fim de compreender a falta de garantias que o Estado colombiano fornece a seus trabalhadores, desculpando-se em interpretações constitucionais que não acomodam o desenvolvimento de um Estado de direito social.

\section{PALAVRAS CHAVE:}

Ato legislativo; princípio da sustentabilidade; bloco de constitucionalidade; antinomia constitucional; compatibilidade de aposentadorias convencionais; regressão de direitos.

\section{INTRODUCCIÓN}

El acto legislativo 1 de 2005 conlleva a la reforma del parágrafo 2 del artículo 48 de la Carta Política, donde se restringe la negociación colectiva en materia pensional en Colombia, dando así lugar a manifestaciones en contra por parte de sindicatos que pactaban en las negociaciones colectivas pensiones convencionales que 
permitían a sus trabajadores acceder a la pensión de vejez con un tiempo menor al exigido por el sistema general de pensiones.

Pese a la expedición de la Ley 100 de 1993, que propugnó por la unificación de los regímenes pensionales, se mantuvieron las condiciones de estos acuerdos protegidos por tratados internacionales como el protocolo de San Salvador o los convenios 87, 98, 151 y 154 de la Organización Internacional del Trabajo (OIT).

Por lo anterior se esbozará la trascendencia social que tiene la protección de los derechos a la seguridad social y la contingencia constitucional que se presenta a partir del Acto Legislativo 01 de 2005, donde se afectan principios rectores del derecho laboral como el indubio pro operario, el principio de favorabilidad, el principio pro omine. No se puede desconocer que la relevancia de un tema que, a futuro, afectará a todos los colombianos. Se busca vislumbrar lo que el Estado hace, a través de interpretaciones erróneas de integración del bloque de constitucionalidad, para poder solventar crisis fiscales con cargo a los mismos trabajadores.

El planteamiento de este artículo analiza la determinación de la Corte Constitucional en la Sentencia SU - 555 de 2014 frente a los tratados internacionales que abordan temas de pensiones convencionales, determinando la afectación a partir de la mencionada reforma constitucional frente al bloque de constitucionalidad y los principios de favorabilidad, sostenibilidad y progresividad de los derechos.

Para efectos del desarrollo del presente artículo se realizará, en primer lugar, un recorrido histórico respecto de la evolución normativa en Colombia en materia pensional, posteriormente se analizarán los principios en tensión, anteriormente descritos, y la integración de estos mismos en la argumentación dada por la Corte Constitucional, atendiendo a jurisprudencia emitida por esta misma corporación.

\section{METODOLOGÍA}

Atendiendo al desarrollo propio de la investigación y la línea de investigación se hace necesario indicar que la presente es una investigación deductiva con paradigma cualitativo, con un punto de vista teórico, usando el método que explicativo, en el cual se busca realizar un análisis teniendo como fuentes documentos especializados de doctrina y jurisprudencia, así como un marco legal que permita por medio de la hermenéutica llegar a concluir soluciones de carácter jurídico.

\section{DESARROLLO DE LA DISCUSIÓN}

\section{Ubicación histórica del derecho a la seguridad social en Colombia}

Para hablar de la seguridad social en Colombia es importante tener en cuenta que en en el país la asistencia es, en un principio, privada. De allí que Arenas Monsalve resalte que:

Lo asistencial se inicia en el país con la asistencia privada, promovida principalmente para atender calamidades de salud, a través de juntas de socorro. Una crónica de la época lo ilustra al describir una epidemia de gripa en Bogotá en 1918 que en una semana arrojo centenares de muertes (Arenas, 2011, Pág. 58).

De acuerdo con lo anterior el Estado colombiano daba cobertura en la salud a las personas que podían acceder a la misma, por lo cual se evidencia la necesidad de que la cobertura se extendiera de igual modo a las personas de escasos recursos. Según Arenas Monsalve (2011) la Clínica San Rafael, es el icono de la combinación de la asistencia privada y pública. El autor encuentra que uno de los precursores de la asistencia pública fue el General Uribe Uribe dado que busca con esta eliminar la caridad.

Ahora bien, la asistencia privada y pública es el punto de partida para entrar a hablar de seguridad social; una figura importante que refleja el inicio de la seguridad social en el país son los montepíos militares, cajas de subsidio de socorro financiero para las familias de los militares, los cuales fueron suspendidos definitivamente en 1917.

[...] finaliza esta experiencia de la organización de un Montepío Militar en nuestro país que, pese a ser una institución clasista, denota la preocupación de los gobernantes por establecer un régimen de protección a favor de las viudas y de los huérfanos de los militares activos y que por no reunir los requisitos de Leyes especiales no tenían derecho a recibir otros beneficios (Arenas, 2011, Pág. 59). 
En este sentido esta era una garantía importante para las familias de los militares y, desde la perspectiva de la seguridad social, fue el inicio para figuras posteriores como la pensión de sobreviviente. De igual forma en la época se establece, mediante decreto del 13 de octubre de 1821 , acreencias a las viudas, huérfanos y padres de los militares.

Otra norma importante fue la Ley 50 de 1886, la cual establecía pensiones para personal civil oficial y los requisitos para obtenerla. Esta pensión a personal civil oficial se hizo extensiva a los educadores y se conoció como "pensión de gracia" ${ }^{1}$ y a esta le siguió la Ley 29 de 1905, que establece los requisitos para que los magistrados accedan a una pensión.

Para 1904 se evidenciaban con claridad los privilegios creados para empleados estatales a quienes sí se les garantizaba una pensión, en contraste con el sector privado que no contaba con esta garantía. El General Uribe Uribe llamó la atención acerca de esta situación y buscó que los trabajadores privados también tuvieran derecho a estas garantías, en ese contexto impulsó la Ley 57 de 1915, sobre accidentes del trabajo.

Un avance importante frente al régimen de seguridad social fue la caja de retiros militares creada con la Ley 75 de 1925 la cual buscaba que el Estado, mediante financiación de aportes de los militares y subvenciones anuales del patrimonio fiscal "debía reconocer sueldos de retiro a los militares, convertibles en pensiones a los beneficiarios en caso de fallecimiento" (Arenas, 2011, Pág. 61), con lo anterior se da inicio a un régimen de pensión para los militares.

Según Arenas Monsalve, estas cajas fueron el inicio de las instituciones de seguros sociales del régimen contributivo. Una en especial, la Caja de Previsión Social de Navegación "Riocaja", genera gran incidencia en materia de seguridad social y negociación colectiva, como se aprecia en su creación, por un laudo arbitral en 1942, donde se establece que "cubriría pagos de cesantías, seguro de vida, indemnización por accidente de trabajo, muerte o invalidez y enfermedad profesional" (Arenas, 2011:63).

1. Otras leyes importantes frente a la adquisición de pensiones de los docentes son la Ley 39 de 1903, Ley 113 de 1913 y la Ley 116 de 1928.
Ahora bien, para el año de 1945, se establece una legislación uniforme en materia de relaciones laborales estableciendo igualdad frente a los beneficios en materia de prestaciones sociales por medio del Decreto Ley 2350 de 1944 y la Ley 6 de 1945, que establece un antecedente importante dado establece la seguridad social a cargo de los empleadores, siendo un punto de partida importante toda vez que genera una mayor responsabilidad por parte de los empleadores.

La importancia de la legislación de 1945 radica en que "[...] creo las prestaciones sociales, fundó la Caja Nacional de Previsión y autorizo la creación de cajas oficiales." (Arenas, 2011: 68). Desde esta perspectiva es importante resaltar que frente a la Caja Nacional se estableció que esta era una persona jurídica autónoma y que su capital se formaría de aportes del presupuesto de la nación, aportes de los empleados y el primer sueldo mensual de todos los trabajadores a nivel nacional.

La Ley 90 de 1946 crea el Instituto Colombiano de los Seguros Sociales como entidad encargada de administrar el régimen de seguros sociales obligatorios. Conocido de manera abreviada como "Seguro" es un ente importante dado que hasta su creación los empleadores eran quienes debían responder por las indemnizaciones, por eso señala Arenas que el Código Sustantivo de Trabajo establece que "todos los patronos estarán obligados a pagar las prestaciones sociales, pero que ellas "dejaran de estar a cargo de los patronos cuando el riesgo de ellas sea asumido por el instituto colombiano de seguros sociales[...]"' (2011: 66). Uno de los mayores problemas del ICSS fue el déficit hospitalario unido a la escases de médicos. Baste decir que para 1958 el déficit del Instituto era de 20 millones de pesos de la época.

Mediante el Decreto 180 de 1956 se implementa el subsidio familiar, posteriormente mediante el Decreto 249 de 1957 se fijan los requisitos para establecer una caja de compensación familiar, de igual modo el Decreto 1521 de 1957 esboza el subsidio familiar como medio de fortalecimiento familiar. Para 1962 se establece que las cajas de compensación podrán destinar el dinero que ahorran del porcentaje autorizado a beneficio social. Frente a lo relacionado con el subsidio familiar el gobierno extiende este beneficio al sector oficial mediante la Ley 58 de 1963. 
Una de las garantías más importantes para los trabajadores de empresas privadas, que generan una mayor estabilidad en la adquisición de pensiones, es la Ley 171 de 1961 la cual busca que se protejan los derechos de los trabajadores para que estos no sean despedidos sin justa causa antes de cumplir los requisitos de la pensión de jubilación, es decir que con esta Ley nace la "pensión sanción".

Hasta el $1^{\circ}$ de enero de 1967 el instituto solo cubría los riesgos de enfermedad y maternidad (EGM) y riesgos profesionales (ATEP). Con la expedición del Decreto 1824 del 12 de julio de 1965 se aprueba el reglamento de inscripción, aportes y recaudo para el seguro de IVM; y el Decreto 3041 del 19 de enero de 1966, se aprueba el reglamento general de este seguro. El reglamento general de IVM estableció que la pensión de vejez se obtiene con el cumplimiento de los requisitos de edad y tiempo de cotización al sistema en cualquier empresa afiliada al instituto (Arenas, 2011: 79).

Ahora bien, teniendo en cuenta que el Seguro entra ya en forma definitiva a reconocer todo tipo de pensiones e indemnizaciones, para dar cobertura en todo el país, comienza a formar oficinas en varios municipios asegurando así una mayor cobertura.

El Decreto-Ley 3135 de 1968 recoge las normas sobre prestaciones sociales a empleados públicos y trabajadores oficiales, otro decreto importante es el 435 de 1971 se ocupó de regular el financiamiento de la seguridad social oficial y las pensiones, por otro lado, los Decreto-Ley 433 de 1971 y 148 de 1976, reorganizan el ICSS a nivel funcional y administrativo.

En 1976 se crea el Fondo Nacional Hospitalario, ampliando la cobertura de la atención de salud. Se expide también la Ley 4 de 1976 busca una mayor seguridad jurídica social para los pensionados y se establecen condiciones más favorables para estos como el reajuste anual del monto pensional.

Mediante el Decreto Ley 1650 de 1977 se transforma el Instituto Colombiano de Seguridad Social y se denomina Instituto de Seguros Sociales (ISS) y se da una separación en las prerrogativas que se tienen dividiendo los seguros en asistenciales y económicos. Este mismo año se constituye una categoría especial de empleados públicos que tienen derecho a la negociación colectiva. De igual modo el Decreto 2879 de 1985 establece que la pensión sanción se integra a la de vejez y, mediante la Ley 50 de 1990, se deja de aplicar la pensión sanción cuando se cumplió la obligación patronal.

La Ley 33 de 1985 se unifica la edad de pensión en el sector público a los 55 años, y la Ley 71 de 1988 crea la pensión de jubilación por aportes, buscando unificar el tiempo para la pensión. Cinco años después se expide la Ley 50 de 1990, la cual flexibiliza las relaciones laborales individuales y fortalece los derechos colectivos, esta ley aumenta de 8 a 12 semanas el descanso remunerado por maternidad y, de igual modo, se promulga ese mismo año la ley 60 , que establece condiciones de retiro de funcionarios públicos.

Posteriormente el Decreto 1160 de 1991 crea la figura de insubsistencia con indemnización y el retiro voluntario mediante bonificación. Mediante Decreto 2148 de 1992 se cambia la naturaleza jurídica del ISS a empresa industrial y comercial del estado y el Decreto 2147 de 1992 modifica las funciones y la estructura del ISS.

La Ley 100 de 1993 crea el sistema de seguridad social integral el cual se encuentra formado por pensiones, salud, riegos laborales y servicios complementarios. Esta ley se expide con el fin de unificar la normatividad en la materia, el sistema está dirigido, controlado y coordinado por el Estado, también da lugar a que se combine la gestión pública y privada, estableciendo la afiliación de trabajadores independientes.

En esta ley se reconoce la pensión de vejez, invalidez y de sobrevivientes para las cuales como requisitos se estipula estar afiliado y cotizar el tiempo señalado. De igual modo se establece la obligatoriedad de afiliarse al sistema y se unifican los regímenes pensionales exceptuando los regímenes de pensión de militares, policías, maestros y trabajadores de Ecopetrol, los cuales tienen un régimen de transición.

Aduce Arenas (2011) que la Ley 797 de 2003 constituye un fortalecimiento en el sistema de seguridad social en materia pensional dado que da mayores prerrogativas frente a los beneficios en los regímenes e introduce recortes significativos en la variables para el cálculo de las pensiones de prima media de igual forma establece múltiples exigencias para el reconocimiento de la pensión de 
vejez. La Corte Constitucional, mediante sentencia C-1056 de 2003, declaró inexequibles los artículos $11,17,18,21,22$ y 23 de esta ley, por cuanto:

no fueron debatidos ni aprobados por las Comisiones Séptimas Constitucionales Permanentes reunidas en sesiones conjuntas, sino que fueron dejados como constancia. A pesar de lo anterior, fueron reintroducidos como artículos nuevos en el pliego de modificaciones de la ponencia para segundo debate en la Cámara de Representantes o incorporados como artículos nuevos durante en segundo debate en el Senado de la República, y fueron aprobados por alguna de las dos Plenarias, para luego ser conciliados en la Comisión Accidental (Corte Constitucional, 2003).

inalmente, el Acto Legislativo 1 de 2005 modifica en materia pensional una serie de garantías pensionales, basándose en el principio de sostenibilidad financiera, y establece el desmonte de los regímenes pensionales exceptuados y especiales y prohíbe los acuerdos pensionales y las pensiones extralegales.

\section{Análisis de los principios en tensión}

Estas son normas que imperan para que se realicen principios en la mayor medida posible en relación a las viabilidades jurídicas. Los principios son mandatos de optimización que pueden ser cumplidos en diversos grados, es decir, su cumplimiento depende de las posibilidades fácticas y jurídicas. Son un mandato de integración, optimización y armonización, puesto que se deben tener en cuenta para el correcto ejercicio de compresión y aplicación de las normas. La libertad del trabajo, obligatoriedad y protección del Estado al trabajo, igualdad, principio realidad, estabilidad laboral, favorabilidad, irrenunciabilidad y garantías mínimas, son uno de los principios fundamentales del trabajo.

\subsection{Principio de favorabilidad}

Según la Sentencia T -559 de 2001 es un principio de carácter constitucional, consagrado en el artículo 53 de la Constitución y 21 del Código Sustantivo del Trabajo (en adelante CST). Para tal caso se debe tener en cuenta que este principio tiene una consideración desde el punto constitucional y legal, el cual consiste en una obligación de todo servidor público a optar por la situación más favorable para el trabajador, en caso de duda de la aplicación e interpretación de las normas jurídicas. A partir de la citada jurisprudencia se puede identificar que pueden surgir más situaciones en las que este principio se puede aplicar, dejando en claro que no solo se tendrán en cuenta cuando se presente discrepancia entre dos normas.

Sin duda alguna, la aplicación del principio en mención ayuda a la consecución de un plano de igualdad entre las partes de una relación laboral, entiéndase que en este caso se puede hablar de una posición dominante en el contrato de trabajo, por eso el grupo de garantías institucionalizadas llevan al trabajador y empleador a someterse a una situación particular que es la ponderación, no de derechos, sino de normas referentes al derecho al trabajo, muchas veces contradictorias entre sí. La favorabilidad contenida en el artículo 21 del CST se establece como un método para resolver conflictos entre disposiciones normativas cuando regulan una misma situación fáctica; dicha tarea corresponde al juez para aplicar la que sea más favorable al trabajador, es decir parcializa un derecho y lo recarga a este mismo. Dicha situación se puede aseverar en el caso de las pensiones y el Estado.

La favorabilidad en aplicación de regímenes pensionales es un estudio sobre el caso en concreto, se considera que, desde el juicio de constitucionalidad, se presenta una confrontación entre normas genéricas. Tal es el caso de la extensa jurisprudencia que surge a partir del cambio de regímenes pensionales con la promulgación de la Ley 100 de 1993, respecto de esto surgió un estudio apartado, caso por caso, donde se presentará el enfrentamiento entre las nuevas exigencias legales para poder acceder a la pensión por vejez.

En cuanto al principio de condición más beneficiosa, según el artículo 53 de la Constitución Política, reconoce la aplicación de interpretación de las fuentes formales del derecho en cuanto a la situación más favorable, así mismo garantiza que el Estado pagará oportunamente el reajuste periódico de las pensiones legales y también reconoce que los convenios internacionales del trabajo, debidamente ratificados, hacen parte de la legislación interna. La condición más beneficiosa para el trabajador se encuentra plenamente garantizada mediante la aplicación del principio de favorabilidad que se consagra en materia 
laboral, en donde corresponde determinar en concreto cuál norma es más ventajosa o benéfica al trabajador.

Es claro que la modificación o derogación de una norma surte efectos hacia el futuro, salvo en el principio de favorabilidad, de tal manera que las situaciones consolidadas bajo el imperio de legislación, objeto de aquella, no pueden sufrir menoscabo.

La diferencia que dista entre favorabilidad, indubio pro operario y condición más beneficiosa se explica en tres sencillas definiciones:

- El principio de favorabilidad suele aplicarse en el momento de resolver cuando existen dos o más normas vigentes susceptibles de emplearse al caso, pero asalta la duda sobre cual aplicar, para que este sea aplicable debe concurrir varias normas, la vigencia de estas al momento de la aplicación y que su análisis sea hecho en su totalidad

- El principio indubio pro operario no se encuentra ante varias normas sino ante varias interpretaciones, entre las cuales el juez debe decidir por la que más beneficie al trabajador

- La condición más beneficiosa se aplica cuando ocurre un cambio de legislación, es decir cuando hay dos normas en pugna y una de ellas se encuentra en tránsito a ser derogada. El juez se encuentra determina si persona titular de derecho se cobijará en la norma derogada, cumpliendo requisitos especiales, o sus derecho será remplazado por la norma posterior que posiblemente le desmejore.

\subsection{Principio de sostenibilidad}

A partir de la reforma constitucional prevista para el artículo 334 de la Constitución Política, se define el principio de sostenibilidad fiscal que impulsó el Acto Legislativo 01 de 2005, donde se modificó el artículo 48 respecto a la extinción de las pensiones convencionales. El artículo 1 del Acto Legislativo 3 de 2011, que reformó el artículo 334 de la Constitución Política, propone racionalizar la economía a través de un marco de sostenibilidad fiscal, el mejoramiento de la calidad de vida de los habitantes en la distribución equitativa de las oportunidades, asegurando de manera progresiva para que se tenga acceso en conjunto al derecho de la seguridad social. En la exposición de motivos se aseguró que la sostenibilidad fiscal es indispensable para alcanzar los fines del Estado Social de Derecho, por lo tanto es un derecho de todos, junto con la colaboración armónica de las ramas del poder público. Así mismo insta a que el Congreso de la República determine el alcance los derechos sociales y económicos consagrados en la Constitución, asegurando la sostenibilidad fiscal con el fin de dar continuidad y progresividad a los derechos reconocidos.

Se considera la sostenibilidad fiscal como condición para el desarrollo del Estado Social de Derecho que, implícito en la Constitución de 1991, constituye y protege a los demás al dar continuidad bajo las diferentes condiciones que enfrente la economía. Se determinó que es importante para el progreso económico y social que se busca, ante una determinada y limitada capacidad para recaudar ingresos para acceder a recursos de financiamiento, establecer una política de gasto que pueda mantenerse en el tiempo, logrando así la reducción de la pobreza y desigualdad.

Al procurar un óptimo empleo de los recursos humanos asegurando a estos los bienes y servicios básicos, la sostenibilidad financiera no es un fin sino un medio para lograr los fines del Estado. Para el proponente del Acto Legislativo la sola acción del Banco de la República, como entre regulador económico del país, no es suficiente para proveer la sostenibilidad fiscal general, es por ello que reitera la necesidad de tener una disposición constitucional expresa, teniendo en cuenta sus limitaciones en cuanto a los recursos, garantía de la prestación y disfrute de los derechos económicos, sociales y culturales.

$\mathrm{Al}$ respecto se cita la Sentencia C-481 de 1999, colocando de manifiesto que la salvaguardia de la capacidad económica de un Estado no puede desbordar las variables económicas, tales como el empleo y el crecimiento. Así mismo, en la Sentencia 579 de 2001, se deja en claro que el legislador debe velar por la preservación de la estabilidad económica nacional, con lo cual este mismo deberá encuadra el concepto de acuerdo a principio de razonabilidad y proporcionalidad. Constituyendo un interés llamado a ser objeto de la regulación con herramientas suficientes para alcanzar una debida interpretación de este principio por parte del legislador. 
Es evidente que, sin el principio de sostenibilidad financiera, se aumenta la crisis del sistema pensional, deteniendo su desarrollo y generando retrocesos en materia de derechos. Con la generación de deuda pública el sistema será insostenible. El acto legislativo mencionado alivió la carga del Estado en materia pensional y lo provisionó de una seguridad jurídica reuniendo a todos los contribuyentes en la Ley 100 de 1993, extinguiendo pensiones anticipadas de vejez y jubilación que resultaban desproporcionadas frente a la realidad social y económica del país.

Contrario a lo anterior, antes de la entrada del ISS, los empleados estaban a cargo de asumir las pensiones en diferentes modalidades como la convención colectiva, pato colectivo o laudo arbitral. A la entrada en operatividad de este instituto se prevén dos regímenes, uno asumido por los empleados y otro por instituto de seguro social; a partir de ello nace la figura de compatibilidad.

La definición del concepto de compatibilidad se encuentra en los artículos 18 y 19 del Decreto 758 de 1990, los cuales señalan:

ARTÍCULO 18. COMPATIBILIDAD DE LAS PENSIONES EXTRALEGALES. Los patronos registrados como tales en el Instituto de Seguros Sociales, que otorguen a sus rabajadores afiliados pensiones de jubilación reconocidas en convención colectiva, pacto colectivo, laudo arbitral o voluntariamente, causadas a partir del 17 de octubre de 1985, continuarán cotizando para los seguros de invalidez, vejez y muerte, hasta cuando los asegurados cumplan los requisitos exigidos por el Instituto para otorgar la pensión de vejez y en este momento, el Instituto procederá a cubrir dicha pensión, siendo de cuenta del patrono únicamente el mayor valor, si lo hubiere, entre la pensión otorgada por el Instituto y la que venía cancelando al pensionado.

PARÁGRAFO. Lo dispuesto en este artículo no se aplicará cuando en la respectiva convención colectiva, pacto colectivo, laudo arbitral o acuerdo entre las partes, se haya dispuesto expresamente, que las pensiones en ellos reconocidas, no serán compartidas con el Instituto de Seguros Sociales. ARTÍCULO 19. SALARIO BASE PARA LAS COTIZACIONES Y APORTES PARA EL SEGURO DE INVALIDEZ, VEJEZ Y MUERTE, DE LAS PENSIONES COMPARTIDAS. Se tomará como salario base para las cotizaciones y aportes que por concepto del seguro de Invalidez, Vejez y Muerte deben cubrir los patronos al ISS para efectos de la compatibilidad de las pensiones de que trata el presente Reglamento, el valor de la pensión que se encuentre cancelando y que se vaya a compartir.

El hecho de que un trabajador acceda a una pensión convencional también corresponde al principio de favorabilidad, que ocurre cuando hay más facilidad de acceder al derecho pensional que las demás personas que se encuentran cubiertos por la ley general. En tales circunstancias la empresa empleadora asuma el pago de la mesada hasta tanto el empleado cumpla la edad y tiempo de la generalidad.

Para la Corte Constitucional en Auto 231 de 2011, que aclara el alcance de la Sentencia T-488 de 2010, resulta lógico que la concurrencia de dos pensiones se dé y por ello se puedan recibir íntegramente dos pensiones, en primer lugar, la extralegal y, posteriormente, la general. Compatibles las dos en caso de cumplirse con los requisitos pactados en convenios y los reglamentados para el Instituto de Seguro Social. La Corte aclaró que las pensiones extralegales carecen de carácter subrogatorio, razón por la cual son obligaciones expresas del empleado, siempre y cuando siguiera cotizando en el Instituto del Seguro Social.

\subsection{Principio de progresividad}

El principio de progresividad se encuentra consagrado en el artículo 26 de la Convención Interamericana de Derecho Humanos, en donde se establece que los Estados partes se comprometen a adoptar providencias, tanto a nivel nacional interno como mediante la cooperación internacional, especialmente económica y técnica, para lograr progresivamente la plena efectividad de los derechos que se derivan de las normas económicas, sociales y sobre educación, ciencia y cultura, contenida en la Carta de la Organización de los Estados Americanos, de igual modo en el artículo 4 del protocolo de San Salvador se resalta que no se puede restringir o menoscabarse ninguno de los derechos reconocidos o vigentes en un tratado en virtud de su legislación interna, excusándose en que determinados derecho se reconocen en menor grado.

En Sentencia SU 225 de 1997 la Corte Constitucional reconoce que este principio es 
tendiente al reconocimiento de prestaciones mayores o superiores a los que ya se había alcanzado en un nivel y, por lo tanto, el Estado debe recurrir con todos sus recursos disponibles para proveer los mencionados derechos; es decir que la protección universal del contenido del derecho sobrepasa el peso del principio de progresividad establecido. Así, el Estado se encuentra obligado a aumentar progresivamente la satisfacción de los derechos sociales y tiene prohibido, al menos en principio, retroceder en los avances obtenidos.

De acuerdo con la Sentencia C- 228 de 2011 el principio de progresividad implica que una vez alcanzado un nivel de protección de un derecho en particular el legislador se debe sujetar a la regla de que esta actuación se presupone inconstitucional o, cuando menos, se debe tensionar frente a principios reconocidos internacionalmente. La Corte entiende que la prohibición a los retrocesos no puede ser absoluta, es por ello que se precave que en situaciones de real crisis el Estado está facultado para tomar estas medidas tendientes a la reorganización del sistema.

[...] se dijo que si se utiliza como presupuesto de justificación de la regresividad de un derecho social el fomento del empleo se debe constatar, "(i) que las medidas no fueron tomadas inopinadamente sino que se basaron en un estudio cuidadoso, y (ii) que el Congreso analizó otras alternativas, pero consideró que no existían otras igualmente eficaces que fueran menos lesivas, en términos de la protección del derecho al trabajo. Y (iii) finalmente debe el juez constitucional verificar que la medida no sea desproporcionada en estricto sentido, esto es, que el retroceso en la protección del derecho al trabajo no aparezca excesivo frente a los logros en términos de fomento del empleo". ( Corte Constitucional, 2004, Sentencia C- 038 de 2004) )

Estas medidas residen en un test de proporcionalidad, en donde el limitador debe proponer estudios donde se verifique si la medida regresiva constituye un fin constitucionalmente legítimo y así mismo se tiene que analizar otras medidas tendientes a lograr el mismo propósito, buscando con esto que el presupuesto no sea el único propósito del cambio regresivo.

Cuando una medida regresiva es sometida a juicio constitucional, corresponderá al Estado demostrar, con datos suficientes y pertinentes, (1) que la medida busca satisfacer una finalidad constitucional imperativa; (2) que, luego de una evaluación juiciosa, resulta demostrado que la medida es efectivamente conducente para lograr la finalidad perseguida; (3) que luego de un análisis de las distintas alternativas, la medida parece necesaria para alcanzar el fin propuesto; (4) que no afectan el contenido mínimo no disponible del derecho social comprometido; (5) que el beneficio que alcanza es claramente superior al costo que apareja. (Corte Constitucional, 2011)

El legislador no puede desconocer que el principio de progresividad es una garantía de los derechos económicos, sociales y culturales. La protección del derecho a la seguridad social va envuelta de unos mínimos estándares de reconocimiento, mínimo que debe ser respetado posteriormente, puesto que este mismo es fijado como un punto de equilibrio en las necesidades básicas. La progresividad implica igualmente una limitación al legislador, por cuanto al momento de tratar de disminuir el beneficio en cuanto a un derecho se encuentra un control constitucional estricto, en donde se debe demostrar que existen razones urgentes para el paso regresivo en el desarrollo del derecho prestacional.

La Corte Constitucional clarificó, en la Sentencia C 789 de 2002, que no se puede hablar de regresividad cuando se está tratando de meras expectativas, ya que con la creación de los regímenes de transición de acuerdo a principio de proporcionalidad el legislador tuvo que haber tenido un control sobre la afectación de estos derechos. Frente al caso en particular, el Acto Legislativo que exceptuó los regímenes especiales responde en determinadas situaciones al principio de confianza legítima reconociendo en régimen de transición descrito.

\section{Bloque de constitucionalidad}

En primera medida es importante señalar que el bloque de constitucionalidad consagrado en la Constitución Política colombiana se establece en el Artículo 93, así:

ARTICULO 93. Los tratados y convenios internacionales ratificados por el Congreso, que reconocen los derechos humanos y que prohíben su limitación en los Estados de excepción, prevalecen en el orden interno. Los derechos y deberes consagrados en esta Carta, se interpretarán de conformidad con los tratados internacionales 
sobre derechos humanos ratificados por Colombia (Asamblea Nacional Constituyente, 1991).

Por lo anterior, se entiende que el bloque de constitucionalidad consta de todos aquellos tratados internacionales que protegen los derechos humanos, los cuales deben ser ratificados. Ahora bien, teniendo en cuenta lo anotado los derechos consagrados en el Protocolo de San Salvador hace parte del bloque y se deben consideran como fundamentales. Al respecto Uprimny afirma que:

En los últimos años, y al menos desde 1995, la categoría "bloque de constitucionalidad", que no había sido nunca usada por la doctrina o por la jurisprudencia colombianas, ha entrado con mucha fuerza en la práctica jurídica nacional. Así, en numerosas sentencias, la Corte Constitucional no sólo ha recurrido a esa expresión sino que, además, esa noción le ha servido de fundamento normativo para tomar determinaciones tan importantes, como las relativas al alcance de la obediencia debida por parte de los militares, o aquellas relacionadas con la fuerza jurídica en el ordenamiento colombiano de las recomendaciones de ciertas instancias internacionales de derechos humanos 1 . Sin embargo, a pesar de su uso creciente, este concepto de "bloque de constitucionalidad" es problemático en la doctrina y jurisprudencia nacionales. Así, esa noción sigue siendo un poco enigmática para muchos operadores jurídicos, que no entienden claramente ni su alcance ni su importancia, y por ello tienden a considerarla un extranjerismo innecesario. (2005: 1)

El alcance del bloque de constitucionalidad suscita una problemática generalizada en cuanto a su aplicación, por lo que resulta de complejo desarrollo el reconocimiento de esta a través de la jurisdicción ordinaria, distinto es afirmar que este sí se puede ver plasmado en las decisiones las Altas Cortes. La falta de criterio jurídico por parte de la justicia permite recordar una vez más que los tratados de la O.I.T tienen que darse más allá de una simple estipulación.

Con ello se deduce que la Corte Constitucional entra a reglamentar el bloque de constitucionalidad a partir de 1995, aunque presenta una problemática de unificación. Por ello es importante tener en cuenta que:

[...] el bloque de constitucionalidad tiene ciertas ventajas y potencialidades democráticas, ya que permite que la Constitución sea más dinámica y se adapte a los cambios históricos, en la medida en que faculta a los jueces constitucionales a tomar en cuenta importantes principios y derechos, que pueden no estar incluidos directamente en el texto constitucional, pero que, en el curso del tiempo, pueden llegar a adquirir una enorme importancia (Uprimny, 2005: 4).

Por otro lado, es claro que el bloque de constitucionalidad sirve como base en el caso de vulneración a derechos humanos, dando asílugar a la implementación de los tratados internacionales que el Estado colombiano ha ratificado en el trascurso de los años, de igual forma se hace necesaria una mayor interpretación por parte de los jueces. Con lo anterior puede determinarse que el bloque de constitucionalidad tiene una importante incidencia en la expedición de leyes, resoluciones, etc. Buscando que no vulneren derechos humanos y derechos fundamentales.

El bloque de constitucionalidad se desarrolla en toda la Constitución, así pues, adicional al Artículo 93, los Artículos 9, 53, 94, 102 inciso 2 y el 214 numeral 2, hacen referencia a los convenios internacionales que el Estado colombiano ratifica.

La Sentencia T-568-99 catalogó los derechos sociales como derechos humanos por lo que en virtud del Artículo 93 de la Carta se considera que todos los instrumentos internacionales de derechos humanos que tratan de derechos sociales hacen parte del bloque de constitucionalidad. Así, tratados internacionales ratificados por Colombia como los convenios de la O.I.T, el Pacto de Derechos Económicos, Sociales y Culturales (PIDESC) y el Protocolo de San Salvador, entre otros, hacen parte del bloque de constitucionalidad (Arango, 2004: 91).

En este sentido desde el año 1999 se entiende que estos tratados hacen parte del bloque de constitucionalidad, aun cuando en la actualidad frente a los convenios que tratan temas en materia laboral deben ser elevados a ser parte del bloque de constitucionalidad, contradiciendo así esta posición, la cual era clara y respetaba los avances frente a los derechos laborales.

Y de igual forma en la Sentencia C-401 de 2005 se establece que:

[...] Lo anterior indica que de ninguna manera los convenios internacionales del trabajo pueden ser considerados simplemente como 
parámetros supletorios en el ordenamiento laboral. Independientemente de la definición acerca de cuáles son los convenios que forman parte del bloque de constitucionalidad, es claro que todos forman parte de la legislación interna, lo que significa que no pueden ser relegados, por regla general, a parámetros supletorios de interpretación ante vacíos normativos en el orden legal.[...] (Corte Constitucional, 2005a).

Conforme a lo anotado a lo largo de la presente investigación para el derecho laboral y de la seguridad social, resulta de vital importancia que los convenios ratificados por Colombia hagan parte del bloque de constitucionalidad, teniendo en cuenta la importancia de garantizar la no regresividad en los derechos que se han adquirido y que se presupone el trabajador puede reclamar.

Se debe resaltar que no todos los tratados internacionales hacen parte del bloque de constitucional, por ello que se tener en cuenta que desde este punto de vista.

La Corte restringe el concepto de bloque de constitucionalidad para entender que no todos los tratados y convenios internacionales ratificados por Colombia hacen parte del bloque de constitucionalidad sino que, salvo remisión expresa de normas superiores, sólo constituyen parámetros de control constitucional aquellos tratados y convenios internacionales que reconocen derechos humanos y que prohíben su limitación en Estados de excepción (Arango, 2004: 84)

Desde esta perspectiva, en Colombia, aunque Estado parte de una gran cantidad de tratados internacionales, pocos de ellos se incluyen en el bloque de constitucionalidad. Esto es debido a que, si bien es cierto cada tratado suscrito y ratificado es importante, solo hay unas disposiciones que no se pueden pasar por alto en la integración y se limitan a aquellas que hablan exclusivamente de derechos humanos. Los relevantes para el caso en concreto, son resaltados en la sentencia T - 568 de 1999:

En este orden de ideas, para la revisión de los fallos de instancia proferidos en el trámite de este proceso, es claro que el bloque de constitucionalidad debe construirse a partir del Preámbulo de la Carta Política, e incluir los Artículos 1, 5, 39, 53, 56 y 93 de ese Estatuto Superior, pues en esas normas están consagrados los derechos que reclama el Sindicato actor como violados; también procede incluir la Constitución de la O.I.T y los Convenios 87 y 98 sobre libertad sindical (tratado y convenios debidamente ratificados por el Congreso, que versan sobre derechos que no pueden ser suspendidos ni aún bajo los Estados de excepción); además, los Artículos pertinentes de la Declaración Universal de los Derechos Humanos, el Pacto Internacional de Derechos Económicos, Sociales y Culturales, y la Convención Americana de Derechos Humanos. Se confrontarán con ellos los Artículos 430 y el 450 del Código Laboral, subrogado por el Artículo 65 de la Ley 50 de 1990 ("casos de ilegalidad y sanciones"), puesto que en ellos se basaron el despido, los fallos de los jueces ordinarios y, en parte, las providencias bajo revisión; y, claro está, la recomendación del Comité de Libertad Sindical de la Organización Internacional del Trabajo (Corte Constitucional, 1999a).

Pese a la existencia del concepto de conceptos de la Corte Constitucional en cuanto a la aplicación del bloque de constitucionalidad, es claro que este se debe a la integración de normas superiores que deben tener en cuenta, no solo en la aplicación para casos en específico, sino que se deben mirar detalladamente al momento de legislar; por ello, aunque no se puede desconocer la ratificación expresa del Estado colombiano en el compromiso real de cumplimiento, esta se ve relegada a una interpretación circunstancial de la prevalencia del derecho internacional sobre la Constitución Política.

La conformación del bloque de constitucionalidad, en atención a los lineamientos normativos dictados como disposiciones de carácter obligatorio, permite al legislador tener en cuenta la necesidad de una coherencia con la normatividad interna. Con la expedición del acto legislativo y su evidente retroceso en materia de derechos laborales no se acata los presupuestos de restringen estas prácticas, así como la limitación al derecho de la negociación colectiva.

Las ventajas que representa la suscripción de los tratados internacionales, en cuanto a interpretación y delimitación de los alcances de los principios laborales encausan, sin lugar a duda, una garantía de seguridad jurídica que se debe ver reflejada en el trato que del legislador da a las perspectivas del derecho laboral y de la seguridad social internacional. Por eso la situación plasmada en la reforma constitucional en comento, al igual que la interpretación dada por la Corte Constitucional, deben someterse a un 
estudio más profundo del caso, donde se evalúen la aplicación de los tratados internacionales que hagan parte del bloque de constitucionalidad.

\section{Antinomia constitucional}

Para determinar qué es una antinomia constitucional inicialmente es importante resaltar la noción de esta según la real academia española (RAE): "1.f. contradicción entre dos preceptos legales. 2.f. contradicción entre dos principios racionales." En este sentido, la contradicción entre dos normas constitucionales se catalogaría como antinomia constitucional, como es el caso del Artículo 48 en su parágrafo 2 y el Artículo 93 de la Constitución. Sobre el particular la H. Corte Constitucional ha determinado:

[...] contradicciones internas del ordenamiento jurídico, y específicamente el de las antinomias constitucionales, ha sido abordado usualmente por la doctrina a partir de la connotación de sistema que se predica del ordenamiento jurídico, y que exige la coherencia interna del mismo. [...] A juicio de Bobbio, "un ordenamiento jurídico constituye un sistema porque en él no pueden coexistir normas incompatibles. [...] Si en un ordenamiento existieren dos normas incompatibles, una de las dos, o ambas, deben ser eliminadas. Si esto es verdad, quiere decir que las normas de un ordenamiento tienen cierta relación entre sí, y que esta relación es una relación de compatibilidad, que implica la exclusión de la incompatibilidad. (Corte Constitucional, 2001b)

Veamos ahora los preceptos constitucionales en tensión. En el caso del articulo 48 parágrafo 2, se dice que: "A partir de la vigencia del presente Acto Legislativo no podrán establecerse en pactos, convenciones colectivas de trabajo, laudos o acto jurídico alguno, condiciones pensiónales diferentes a las establecidas en las Leyes del Sistema General de Pensiones"(Presidencia, 2005). Es decir que prohíbe la negociación colectiva en materia pensional. En contraste el Artículo 93 especifica que:

ARTICULO 93. Los tratados y convenios internacionales ratificados por el Congreso, que reconocen los derechos humanos y que prohíben su limitación en los Estados de excepción, prevalecen en el orden interno. Los derechos y deberes consagrados en esta Carta, se interpretarán de conformidad con los tratados internacionales sobre derechos humanos ratificados por Colombia (Constitución Política 1991).

En esta línea argumental al bloque de constitucionalidad se deben incorporan los convenios de la O.I.T., entre ellos el 87, 98, 151 y 154. Este último, el Convenio 154, regula la negociación colectiva y no restringe de manera alguna los temas sobre los que se pueden tratar en las negociaciones, ya que es una forma de mejorar las condiciones de los trabajadores y es un acuerdo de voluntades con el empleador el cual conlleva beneficios para ambos.

Para determinar porque existe antinomia entre estas dos normas es importante desarrollar algunos conceptos y la posición que la Corte Constitucional ha desarrollado frente a la antinomia.

Adoptando uno u otro de los conceptos de norma, se puede definir a una "antinomia" en uno u otro de los métodos siguientes: a) es un sistema jurídico existe antinomia siempre que indeterminado comportamiento esta deónticamente calificado en dos modos incompatibles por dos diversidad normas pertenecientes al sistema; o bien b) en un sistema jurídico existe una antinomia siempre que para un determinado supuesto de hechos estén previstas dos consecuencias jurídicas incompatibles por dos normas diversas pertenecientes al sistema. (Guastini, 2008: 71-72).

Desde esta perspectiva es claro que la antinomia se presenta cuando dos normas del mismo rango jerárquico crean una contradicción, es decir que se puede presentar en todo tipo de ordenamiento jurídico, por lo que es de vital importancia determinar que, por la interpretación, también puede presentarse antinomia, en este sentido esta puede:

Hay que insistir en que una antinomia es un conflicto entre normas y no entre disposiciones normativas. Con esto se quiere decir: en primer lugar, que una antinomia puede (en muchos casos) se evitada, prevenida, por medio de la interpretación; en segundo lugar, que una antinomia puede ser creada por la interpretación; en tercer lugar, que una antinomia puede solo presentarse con una interpretación ya realizada; en cuarto lugar, que , en consecuencia, una antinomia abre no un problema interpretativo (y por tanto 
no puede ser resuelta por vía de la interpretación), sino un problema de otra naturaleza. Para resolver la antinomia hay que "eliminar" una de las dos normas de conflicto (o, quizá ambas) (Guastini, 2008: 71-72).

Conforme a lo anterior, es evidente que al tener dos normas que están creando una antinomia es importante determinar que no pueden seguir coexistiendo luego de evidenciarse la existencia del fenómeno jurídico, por lo que se debe suprimir del ordenamiento al menos una de estas normas para que no continúe existiendo dicha contradicción y así no generar inseguridad jurídica, ya que esto conllevaría a que la sociedad no confié en las normas, y muchos menos en la forma en la que se imparte justicia.

Desde otra perspectiva, según el Cuarto Tribunal de Materia Civil del Primer Circuito (México), teniendo en cuenta el Amparo Directo 293/2009 estableció que la antinomia es:

ANTINOMIAS O CONFLICTOS DE LEYES. CRITERIOS DE SOLUCIÓN. La antinomia es la situación en que dos normas pertenecientes a un mismo sistema jurídico, que concurren en el ámbito temporal, espacial, personal y material de validez, atribuyen consecuencias jurídicas incompatibles entre sí a cierto supuesto fáctico, y esto impide su aplicación simultánea (Tribunal de Materia Civil del Primer Circuito (México Amparo Directo 293/2009).

De esta manera las consecuencias jurídicas incompatibles crean una ruptura jurídica, ya que al existir dos normas que se contradicen deben determinar que norma aplicar, en la jurisprudencia citada se establecen posibles formas de solución a la antinomia, entre ellas el criterio jerárquico que, al existir la contradicción entre normas, buscara la subordinada que se opone a la ley subordinante, pudiendo así retirarla del ordenamiento jurídico, dado que la norma subordinante es aquella que debe coexistir en el ordenamiento. El criterio cronológico establece que la norma creada con anterioridad queda abrogada tácitamente por la nueva ley, por lo cual la que debe permanecer en el ordenamiento jurídico es la nueva. El de especialidad se aplica cuando una de las normas es general y la otra específica, para este caso la norma que subsiste en el ordenamiento jurídico es la específica,
Otro de los criterios es el de competencia para el cual tienen en cuenta las siguientes ponderaciones:

a) que se produzca un conflicto entre normas provenientes de fuentes de tipo diverso; b) que entre las dos fuentes en cuestión no exista una relación jerárquica (por estar dispuestas sobre el mismo plano en la jerarquía de las fuentes), y c) que las relaciones entre las dos fuentes estén reguladas por otras normas jerárquicamente superiores, atribuyendo -y de esa forma, reservando- a cada una de ellas una diversa esfera material de competencia, de modo que cada una de las dos fuentes tenga la competencia exclusiva para regular una cierta materia. Este criterio guarda alguna semejanza con el criterio jerárquico, pero la relación de jerarquía no se establece entre las normas en conflicto, sino de ambas como subordinadas de una tercera (Cuarto Tribunal Colegiado en Materia Civil del Primer Circuito de México, 2009).

El criterio de la prevalencia también puede tenerse en cuenta para solucionar la antinomia, en este concepto debe prevalecer alguna de las dos normas, independientemente de la jerarquía o especialidad, así pues la antinomia se presenta cuando las dos normas tienen el mismo rango jerárquico, no podemos decir que hay antinomia entre una ley y una ordenanza, toda vez que siempre primara la que jerárquicamente tenga más peso, mientras que al ser del mismo orden deberá determinarse si se elimina del ordenamiento jurídico una de las normas o las dos.

Para el caso en concreto, la antinomia constitucional, no es un tema abordado con absoluta claridad por la Corte Constitucional. Este un problema que no exceptúa unas verdaderas consideraciones jurisprudenciales donde establezcan reglas de exclusión o de complementariedad que determinen un derrotero de interpretación al momento de su aplicación.

Así, la Sentencia C-1287 de 2001 determina que:

El problema de las antinomias o contradicciones internas del ordenamiento jurídico, y específicamente el de las antinomias constitucionales, ha sido abordado usualmente por la doctrina a partir de la connotación de sistema que se predica del ordenamiento jurídico, y que exige la coherencia interna del mismo. (Corte Constitucional, 2001b). 
De manera complementaria la Sentencia C-132 de 2012 establece:

[...] Y, con base en las reglas para la solución de las antinomias (métodos jerárquico, cronológico y de la especialidad) debería aplicarse el primero, el jerárquico, puesto que el Artículo segundo está en el Título Primero (de los principios fundamentales) $\mathrm{y}$, por ende, al consagrar el principio debe aplicarse sobre otra norma (Artículos 334, 339 y 346 modificados), ya que estos últimos al no consagrar un entenderse como normas "inferiores" frente a lo regulado en el Artículo 2 (que contiene un principio)".(Corte Constitucional, 2012).

Es decir que se estima en cierto modo que las soluciones frente a las antinomias que se presentan en el ordenamiento jurídico pueden ser jerárquicas, cronológicas y de especialidad, de igual forma también han establecido en la Sentencia C-1287 de 2001:

De manera general, la filosofía jurídica contemporánea, con miras a establecer fórmulas para la resolución de antinomias, especialmente de las que se presentan dentro de las constituciones, se ha preocupado por precisar la diferencia que existe entre los valores, los principios y las reglas constitucionales ${ }^{2}$ (Corte Constitucional, 2001b).

Por lo anterior, es importante que se establezca si la antinomia se presenta entre reglas, principios o valores y para determinar de qué forma se resolverá el problema y con los adecuados criterios hermenéuticos. En ese orden de ideas la Sentencia C-439 de 2016 establece:

[...] la Corte puso de presente que existen al menos tres criterios hermenéuticos para solucionar los

2. En lo que concierne a la noción de valores constitucionales, es posible apreciar un acuerdo en cuanto al contenido esencial de dicha noción en los autores que abordan el tema. En primer lugar la doctrina coincide en considerar que las normas que reconocen valores son de naturaleza abstracta e inconcreta; para algunos son normas que orientan la producción e interpretación de las demás normas, y que en tal condición fijan criterios de contenido para otras normas; para otros, las normas que reconocen valores al igual que las que consagran principios, determinan el contenido de otras normas, y aquéllas sólo se diferencian de éstas por su menor eficacia directa, aplicándose estrictamente en el momento de la interpretación. Lo cierto es que en todas las anteriores formulaciones subyace la idea de que las normas que reconocen valores condicionan las demás normas, y tienen un contenido abstracto y abierto, es decir, están formuladas como cláusulas generales que determinan criterios interpretativos del resto del ordenamiento (Sentencia C-1287 de 2001) conflictos entre Leyes: (i) el criterio jerárquico, según el cual la norma superior prima o prevalece sobre la inferior (lex superior derogat inferiori); (ii) el criterio cronológico, que reconoce la prevalencia de la norma posterior sobre la anterior, esto es, que en caso de incompatibilidad entre dos normas de igual jerarquía expedidas en momentos distintos debe preferirse la posterior en el tiempo (lex posterior derogat priori); y (iii) el criterio de especialidad, según el cual la norma especial prima sobre la general (lex specialis derogat generali). Con respecto a este último criterio, se sostiene que, en tales casos, no se está propiamente ante una antinomia, en razón a que se entiende que la norma general se aplica a todos los campos con excepción de aquél que es regulado por la norma especial, con lo cual las mismas difieren en su ámbito de aplicación. (Corte Constitucional, 2016).

En consonancia con lo anterior, teniendo en cuenta el Artículo 48 parágrafo 2, y el Artículo 93 constitucionales, se presenta una antinomia, dado que las normas se contradicen teniendo en cuenta que una, en atención al Convenio de la O.I.T, permite negociar frente a todo tipo de temas en las convenciones colectivas, en la otra (Artículo 48, reformado por parte el Acto Legislativo 1 de 2005) se prohíbe la negociación frente a las pensiones convencionales.

Frente al problema evidenciado es claro que debe establecerse una solución. Al ser dos normas de rango constitucional, y de carácter especial, se puede plantear como solución el criterio del principio cronológico el cual, indica que:

es aquel principio en virtud del cual: en el caso de conflicto entre normas provenientes de fuentes jerárquicamente equiparadas (o sea, dispuestas sobre el plano en la jerarquía de las fuentes) y provistas de la misma esfera de competencia la norma proveniente de la fuente anterior en el tiempo debe considerarse abrogada (y por lo tanto debe ser desaplicada) (Guastini, 2008: 5).

Desde esta perspectiva es importante tener en cuenta que el principio cronológico para la solución de la antinomia tiene como base fundamental que las normas sean del mismo rango jerárquico, es decir que aplica para este caso. Además la Corte Constitucional debe analizar la exposición de motivos del Acto Legislativo 01 de 2005, que explica que la prohibición de negociaciones colectivas frente 
a pensiones convencionales se hace necesaria, según lo expuesto por el gobierno, por el principio de sostenibilidad financiera.

En este sentido y atendiendo lo que la Corte aduce de igual forma en la Sentencia SU 555 de 2014, que no hay contradicción entre una y otra norma al entender que se han preservado los derechos adquiridos y que en cuanto al vencimiento de los mismos el término inicialmente estipulado se refiere a que se mantiene para quienes hayan alcanzado una expectativa legitima de acuerdo con los requisitos de ley.

(...) que se respeten los derechos adquiridos y las expectativas legítimas, que es lo mismo que garantiza el Acto Legislativo 01 de 2005 tanto en el Parágrafo transitorio segundo como en el tercero, en los que establece una regla para derechos adquiridos y también una regla de transición para garantizar que se satisfagan las expectativas legítimas de pensión (Corte Constitucional, 2014) .

La Corte finalmente resuelve el problema de la contradicción a nivel jerárquico, pero no ten tensión con los artículos 53 y 93 constitucionales, sino con respecto al artículo 478 del Código Sustantivo del Trabajo, así:

De manera que, con base en el principio de supremacía constitucional que conlleva al de interpretación conforme a la Constitución y al de eficacia de la misma, es posible concluir que quienes pretendan el reconocimiento de la pensión de jubilación de acuerdo con una convención colectiva cuyo término inicialmente pactado es anterior a julio de 2005 pero que se renovó automáticamente durante varios años consecutivos por seis meses, sólo tendrían derecho a pensionarse si adquieren su derecho antes del 31 de julio de 2010 (Corte Constitucional, 2014).

Para los autores la Corte deja en un limbo jurídico la antinomia dilucidada, pues es necesario que esta entre a estudiar conforme a lo expuesto en la sentencia la importancia de la sostenibilidad financiera y aplique, de acuerdo con el criterio cronológico, la solución frente a la prohibición en materia de negociaciones colectivas, pues, como se evidencia, los trabajadores no podrán llegar a establecer condiciones pensiónales distintas en materia de pensiones a las establecidas por el ordenamiento jurídico.

\section{Fines del Acto Legislativo 01 de 2005}

La cobertura del sistema de seguridad lleva al Estado Social de Derecho a una participación activa en el mismo, tanto así que se lo propone como uno de sus fines. Este derecho hace parte de las necesidades básicas sociales; más que un derecho individual, lleva un conjunto de situaciones sociales que depende del cumplimiento de este para poder atender a contingencias de la vida diaria de los colombianos.

El Estado entonces, para maximizar el bienestar de sus asociados, debe enfrentarse a la restricción presupuestal; ejemplo de ello es el Artículo 48 de la Constitución Política que estableció la Seguridad Social como un servicio público esencial, además de su carácter de derecho fundamental con dimensión prestacional, en donde "otorgó una serie de derechos explícitos, sin preguntarse por la restricción presupuestaria que enfrentaba el Estado para garantizar los derechos y prerrogativas creadas". Lo cierto es que, al establecer la seguridad social en esos términos, es fácil concluir que la pensión, como prestación económica encaminada a suplir necesidades básicas, en efecto, se enmarca en el concepto denominado gasto público social. (Jaramillo, 2014: 4)

El cambio de las políticas pensionales debe tener su sustento en el interés general; principio que se encuadra como fundamental aplicable en materia laboral y de seguridad social, enfrentando así la aplicación de una norma vigente con una derogada. El principio de la condición más beneficiosa se ve representado en el ejercicio jurídico de incertidumbre jurídica cuando el legislador no crea un régimen de transición.

El principio de sostenibilidad financiera elevado a rango constitucional, y expresado en $\mathrm{su}$ mejor ejemplo a través del Acto Legislativo 01 del 2005, deja ver la posición de la Corte respecto a la aplicación del principio de progresividad y su limitación en cuanto a recursos y posibilidades que tenga un Estado para su implementación inmediata; la cohesión entre estos dos principios depende exclusivamente de la adecuada disposición de recursos limitados, de acuerdo a las necesidades primordiales de la población.

El Acto Legislativo 01 de 2005 trajo consigo la inclusión, dentro de la Constitución, del principio 
de sostenibilidad financiera del sistema general de seguridad social, sustentado en su exposición de motivos la garantía del derecho de todos los ciudadanos a obtener una pensión, dando prevalencia al interés general. Esto es apoyado por la Corte y en concordancia con la solvencia económica planeada para mitigar la crisis del sistema, se condicionó cualquier gasto público a este principio, afectando la obtención de derecho económicos, sociales y culturales, bien sea en el sentido de su restricción a un mínimo o una garantía a futuro que busca que la demanda actual de los mismos no acabe con el capital disponible. En ese sentido es posible pensar que en confrontación de los Artículos constitucionales 53, 93 y 94, frente a la integración de la Constitución de la O.I.T, la independencia de alcance de los tratados internacionales no se puede ver restringida en pro de la aplicación de beneficios generales para acceso a la seguridad social; reconocido esto como la condición más beneficiosa.

La garantía de la progresividad de los derechos en general ha venido a ser el principio de sostenibilidad fiscal, como criterio orientador, donde se tiene en cuenta la disponibilidad de los recursos, siempre colocando como direccionamiento el interés general.

A partir de la Sentencia de la Corte Suprema de Justicia, radicado 41.695 del 2 de mayo de 2012, se interpreta que la sostenibilidad financiera pasa de ser un simple principio orientador a una regla para el legislador, sin desconocer los derechos adquiridos y las meras expectativas cubiertas a través de regímenes de transición.

Ya la Sentencia C- 258 de 2013 había colocado en evidencia que Colombia era el cuarto país con el pasivo pensional más alto del mundo $(170 \%$ del PIB) y que, adicional a ello, se tenía un grave problema de cobertura, dejando como justificante la desproporción entre afiliados ( 11.5 millones de personas) y cotizantes activos (5,2 millones).

La Corte resalta la homogenización de los requisitos y beneficios pensionales para lograr equidad y sostenibilidad eliminando regímenes especiales, exceptuando los expresamente señalados en el acto legislativo. Anticipando la finalización del régimen de transición, salva el cumplimiento del requisito mínimo de haber cotizado 750 semanas; la eliminación de la mesada 14 y constituyendo el aumento gradual de las semanas de cotización hasta las 1300 semanas.
Así mismo el acto legislativo se propuso como principios básicos del sistema general de pensiones, la garantía de sostenibilidad financiera, cumplimiento de los requisitos legales, unificación de los requisitos y beneficios, restricción de pensiones convencionales, liquidación sobre factores efectivamente cotizados y limites en el valor de las pensiones. Como se puede observar la búsqueda para lograr la recuperación del sistema pensional llevó al legislador a tomar en cuenta reiteradamente límites tajantes en cuanto al cumplimiento de sus obligaciones pensionales, no se puede contraria que este Acto Legislativo tuvo en cuentas más factores económicos que beneficios para el trabajador.

El Acto Legislativo 1 de 2005 establece en su parágrafo 2 lo siguiente:" A partir de la vigencia del presente Acto Legislativo no podrán establecerse en pactos, convenciones colectivas de trabajo, laudos o acto jurídico alguno, condiciones pensionales diferentes a las establecidas en las Leyes del Sistema General de Pensiones". De esta manera el Acto Legislativo restringe la negociación colectiva en materia pensional.

El soporte jurídico para llegar a la expedición del Acto Legislativo 1 de 2005 es regular completamente lo establecido en la Ley 100 de 1993 y permitir sostenibilidad económica y financiera para el Estado colombiano. No obstante, esta reforma conlleva a la eliminación de los regímenes especiales y exceptuados de pensión, prohibió el derecho de la negociación colectiva en materia pensional, modificó el régimen de transición establecido en la Ley 100 y suprimió la mesada catorce.

Para Valero Rodríguez (2012), el Acto Legislativo tiene cuatro reformas importantes. La primera es la eliminación de los regímenes especiales y exceptuado, desde este punto de vista entran a regir solo los regímenes pensiónales establecidos por la Ley 100 de 1993, dejando únicamente los regímenes privilegiados vigentes. Así pues a excepción de los regímenes especiales la población deberá regirse por los requisitos y tipos pensiónales estipulados en la Ley 100, el segundo punto establecido es la restricción de los derechos de negociación en materia pensional, desde esta perspectiva es claro que limitan la negociación colectiva y aparte limitan la vigencia de los acuerdos dado que estipulan que estos expiran el 31 de julio de 2010. 
En tercer lugar, se establece la modificación del régimen de transición dado que se deja de lado la transición estipulada en la Ley 100 y, como requisito sine qua non, se debe cumplir con la edad y tiempo laborado dado que ya no se puede estipular una forma distinta de pensión.

\section{Determinación de la Corte Constitucional en la Sentencia SU - 555 de 2005}

La Sentencia SU - 555 de 2014 surge en atención a las sobrevinientes reclamaciones emanadas por trabajadores de las empresas ETB, ECOPETROL y Banco de la Republica, para la obtención de las pensiones pactadas en convenciones suscritas con anterioridad a la vigencia del Acto Legislativo 01 de 2005. Las acciones de tutela instauradas en contra de las entidades ya mencionadas resultan del proceso posterior a la fecha fijada por esta reforma constitucional mencionada como límite para la configuración de los requisitos establecidos en las convenciones para obtener la pensión de jubilación. Dentro del trámite de resolución de los fallos de tutelas, cuyo conocimiento en aplicación del Artículo 54 del reglamento de la corporación, fue avocado por la sala plena de la Corte Constitucional en sesión del 14 de diciembre de 2011, y mediante providencia del 16 de diciembre de 2011 se decidió la acumulación de procesos. (Corte Constitucional, 2014).

Así mismo se explica que la sobreviniente interposición de acciones de tutela eran un efecto esperado posterior al 31 de julio de 2010, plazo máximo para que se configuraran los derechos de los reclamantes. Esta situación abrió la puerta para que la Corte Constitucional diera una decisión definitiva a la incertidumbre jurídica en la que se encontraban las personas que cumplían sus los requisitos pactados poco tiempo después de la finalización de la transición dada al Acto Legislativo 1 de 2005.

Conforme a lo señalado en el estudio de los casos en particular que realiza la Corte, las acciones de tutela acumuladas, los accionantes reclamaron como vulnerados sus derechos fundamentales a la vida digna, la igualdad, el trabajo en condiciones dignas, justas, libertad sindical y mínimo vital. La situación jurídica planeada desde el principio observó un estudio sobre la subsidiariedad del mecanismo de tutela, también acogió temas de estudio a la afectación al mínimo vital, se consideró reiteradamente que los accionantes tenían otro medio de defensa judicial idóneo y eficaz, así mismo se verificó que no existió perjuicio irremediable que justificara la invocación de la tutela. En las diferentes instancias el juez de tutela no decidió entrar a estudiar de fondo la vinculatoriedad de las recomendaciones alegadas por las partes como de obligatorio cumplimiento, relegando esta tarea a jueces de jurisdicción ordinaria. Así mismo no se entendió afectado el mínimo vital o un perjuicio irremediable puesto que los accionantes aun laboraban, contando con un salario mensual.

Respecto a la tensión de derechos, la Corte en la mencionada sentencia de unificación resalta las intervenciones de la Comisión Colombiana de Juristas, Procurador General de la Nación y Ministerio del Trabajo; la Comisión Colombiana de Juristas reconoce que existe pugna entre dos normas de rango constitucional, tal como lo es el articulo 48 y los convenios debidamente ratificados e integrados por el bloque de constitucionalidad. Rescatan que Colombia tiene una obligación internacional de adecuar sus normas para no generar este tipo de contradicciones que ponen en peligro la seguridad jurídica y resaltan la prevalencia de los tratados internacionales y principios pro homine, favorabilidad e indubio pro operario, así entonces se protegen los derechos humanos en general y en particular los de los trabajadores. Por otra parte cuestiona las posiciones tomadas por los jueces de tutela, al calificar que los casos presentados a través de la acción de tutela no era el medio idóneo para hacer efectivas las reclamaciones, indagando si en el ordenamiento jurídico existen otros medio para reclamar las recomendaciones de la O.I.T a nivel interno.

Por su parte, el procurador general de la nación afirmó que el Acto Legislativo 01 de 2005 tiene como finalidad eliminar privilegios que desbordan las finanzas del sistema de seguridad social, consideró que no existió una aplicaron súbita y repentina puesto que se dio un tiempo prudencial para poder reunir los requisitos. Reafirma su posición resaltando que las recomendaciones no son normas creadoras de obligaciones sino solo directrices. 
Para el Ministerio del Trabajo no es procedente hacer el estudio de constitucionalidad del Acto Legislativo 01 de 2005 a través de acciones de tutela, señala que el estudio de constitucionalidad se realizó previamente a la integración del Acto Legislativo al Artículo 48. Sustenta que la rica reforma no vulnera el bloque de constitucionalidad al tener en cuenta que se sustrae el tema pensional de la negociación colectiva para preservar la sostenibilidad financiera y hacer efectivos los principios de equidad, igualdad material, seguridad jurídica y coherencia del sistema jurídico.

La seguridad social, al ser un servicio público, se permite fijar un marco que asegure la universalidad y cobertura general del sistema, esta reforma es una respuesta legítima a la crisis, la uniformidad desembocaría en la disminución de la inequidad social.

El problema jurídico suscitado a partir de la controversia constitucional lleva a la Corte Constitucional a analizar si, en primera medida, existen otros medios de defensa judicial para la protección de los derechos fundamentales invocados por los demandantes. Además analiza temas de nueva observancia como la vinculatoreidad de las recomendaciones de la O.I.T y la contradicción constitucional a la prevalencia de los tratados internacionales en Colombia.

La Corte Constitucional se propuso establecer si los derechos reclamados fueron vulnerados por las entidades accionados al negar la pensión de jubilación, estableciendo en primera medida si estas actuaciones contravenían las recomendaciones dadas por el Comité Sindical de la O.I.T. De este estudio se despende el análisis del contenido de las recomendaciones de este ente internacional frente al Acto Legislativo 01 de 2005, así como el lugar que ocupan estas en el ordenamiento jurídico interno.

En cuanto a la procedencia de las acciones de tutela se reconoce, a través de reiterada jurisprudencia, que este mecanismo requiere tres condiciones para ser procedente: i) que no exista de otro medio judicial a través del cual se pueda resolver un conflicto relacionado con la vulneración de un derecho fundamental; ii) que, existiendo otras acciones, estas no resultan eficaces o ideales para la protección del derecho a que se trate, y iii) cuando existiendo acciones ordinarias resulte necesaria la intervención de un juez de tutela para evitar un perjuicio irremediable. (Corte Constitucional, 2004)

Para la Corte Constitucional los jueces que conocieron de los casos en primera medida, no son quienes tienen que dirimir un conflicto de normas de esa magnitud, pese a que existan procesos en la vía ordinaria esta controversia no podría versar sobre el simple cumplimiento de requisitos para acceder a un derecho. El talante del problema jurídico concuerda con un estudio profundo y definitivo que cierre los vacíos jurídicos aun inconclusos por el Acto Legislativo 01 de 2005.

En consecuencia de los anteriormente señalado, la Corte Constitucional entrara a estudiar la finalidades del Acto Legislativo en donde señala que el principal objetivo de este fue unificar los requisitos y beneficios pensionales para lograr una mayor igualdad, equidad $y$ sostenibilidad en el sistema de seguridad social, eliminado regímenes pensionales, anticipando la finalización del régimen de transición de la Ley 100 de 1993 y aumentando progresivamente las semana cotizadas para poder acceder a pensión por jubilación.

Con la expedición de la reforma constitucional se establecieron como principios la garantía de sostenibilidad financiera del sistema de pensiones, cumplimiento de requisitos legales, unificación de requisitos y beneficios pensionales, imposibilidad de hacer pactos o convenciones colectivas como beneficios pensionales superiores, liquidación sobre factores efectivamente cotizados y limite al valor de las pensiones.

La Corte Constitucional reconoce que se respetan los derechos adquiridos de acuerdo a lo señalado en el parágrafo transitorio número 2 , puesto que no afecta a los pactos anteriores a la entrada en vigencia del Acto Legislativo manteniendo el término inicialmente pactado. Para la Corte se crea un régimen transitorio que va desde el 29 de julio de 2005 al 31 de julio de 2010, protegiendo así las expectativas legítimas, como también se admiten las prórrogas de los acuerdos que se den en el tiempo estipulado pero no superior a la fecha límite.

En cuanto a la vinculatoriedad de los tratados internacionales de la O.I.T es recordado a través de 
un extenso registro de jurisprudencia ${ }^{3}$; referente las recomendaciones emitidas por los órganos del ente internacional resalta que se debe tener en cuenta la diferencia entre la recomendación en general dadas por la O.I.T y las de los órganos de control de esta misma entidad. Según el Artículo 19 de la Constitución de la O.I.T las recomendaciones no son normas creadoras de obligaciones sino meras directrices, pero resaltó que, contrario a ello, existen órganos de control que pueden emitir recomendaciones vinculantes, así el Comité de Libertad Sindical es un órgano de control de la O.I.T que somete sus decisiones al consejo de administración de esta misma organización.

Teniendo en cuenta lo anterior, sin este tipo de recomendaciones ninguno de los derechos ratificados por el Estado tendría razón alguna de ser protegidos por el mecanismo de queja, si en este mismo no existiría un mecanismo de coerción que obligue al cumplimiento de los acuerdos internacionales dentro de la O.I.T. La Corte Constitucional considera que estas recomendaciones no deben ser ignoradas puesto que generan tres tipos obligaciones: i) ser acogidas y aplicadas por autoridades administrativa, ii) servir de base para presentación de proyectos legislativos, iii) orientar el sentido de los jueces de tutela. (Corte Constitucional, 2014.). A partir de la Sentencia C- 567 de 2000, la Corte Constitucional manifestó que el estudio se debe realizar en conjunto, es decir la norma demandada junto con la norma superior y los posibles tratados internacionales afectados, dando así aplicabilidad en su contexto al bloque de constitucionalidad.

A lo largo de todo el análisis la Corte Constitucionalidad reconoce la vinculatoriedad de los tratados internacionales junto con las recomendaciones emitidas por los órganos de control de la 0.I.T, resaltando que el derecho a la libertad sindical y negociación colectivas son protegidos por la reforma constitucional, por lo que a su vez la delimitación de principio de orden público son delimitaciones dadas por los Convenio internacionales .

Frente al tema, la Corte Constitucional apoya su interpretación y posterior decisión en la Sentencias

3. Especialmente las Sentencias SU 039 de 2009, donde se estudió el rango normativo de los convenios internacionales, y la Sentencia T - 568 de 1999 donde de trato la inclusión de los tratados al bloque de constitucionalidad.
C-035 de 2005, C - 401 de 2005, C - T- 285 de 2006 y la Sentencia T- 171 de 2011; donde se aclaró que el carácter vinculante de las recomendaciones dependía de que fuera emitida por el órgano de control en el tema de controversia y la respectiva aprobación por el Consejo de Administración de la O.I.T, no obstante estas recomendaciones se condicionan a la interpretación y alcance de los órganos internos. La amplitud de dicho margen varía según el grado de especialidad de la recomendación dada y si esta prevé alternativas de solución. Esto deviene de la libertad de los Estados de gestionar su normatividad interna de acuerdo a sus necesidades dando paso a la interpretación.

La Corte Constitucional reitera, en cuanto a la naturaleza jurídica de las recomendaciones y los tratados internacionales, se deben cumplir procedimiento de ratificación para poder integrar el bloque de constitucionalidad, situación que no ocurre con las recomendaciones. Recalcan que en principio que estas formas de manifestación de la O.I.T solo recogen directrices y no solo instrumentos que obliguen a los Estados, salvo en la situación anteriormente planteada.

Como se había estudiado, las recomendaciones levadas por la OIT nacen a partir de las quejas elevadas por los trabajadores de los sindicatos ATELCA -ETB, SINTRAISA, CHIVOR, SINTRACHIVOR y SINTRAISAGEN, la Organización Internacional del Trabajo se pronunció criticando los efectos retroactivos de la reforma así como la modificación por parte del Estado al Convenio afectando así tanto a la negociación colectiva como los derechos adquiridos. La OIT resalta que la negociación colectiva implica en proceso de concesiones mutuas y certeza razonable de que se mantendrán las obligaciones pactadas, si esto se considerar frente a los derechos conexos a la negociación en pensiones extralegales, no puede haber entonces expectativas razonables ni confianza de los acuerdos afectados por esta reforma. La OIT concluye que se debe considerar los efectos del Acto Legislativo en cuanto a las prórrogas de los convenios que surtan sus efectos posteriores al 31 de julio de 2010.

En segundo pronunciamiento la OIT manifestó que la unificación del sistema pensional no afecta necesariamente el derecho a la negociación colectiva, sin embargo, se puede considerar las pensiones como un sistema complementario dentro del sistema general de pensiones. La OIT no entra a 
fondo en el estudio del principio de sostenibilidad financiera, eje central del acto legislativo, pero así mismo se abre la puerta a la discusión de las pensiones extralegales en empresas del orden privado y público, puesto que, como se ha visto, la carga real del financiamiento de las pensiones atañe al empleador, siendo así que esto solo afectaría a los recursos públicos si se condenan en este tipo de pensiones a empresas del Estado.

La Corte Constitucional entra en el estudio de las recomendaciones de la OIT, manifestando que encuentra acertada su misma interpretación al sostener que las convenciones se mantendrán hasta el plazo máximo del 31 de julio de 2010, pero no se entendió valida alguna prorroga pactada en la convenciones. Se reiteró que el Acto Legislativo no desconoce derecho adquiridos por pactos y convenciones colectivas, puesto que estos no se han integrado al patrimonio de la persona. La Corte señaló que se vulnera los derechos adquiridos cuando una ley afecta situaciones jurídicas consolidadas que afecten a un derecho de carácter subjetivo que ha ingresado al patrimonio, que para el caso en concreto, considera solo meras expectativas. También se respeta las expectativas legitimas de los trabajadores que estaban en vía de consolidar su derecho antes de la fecha límite de acuerdo con los pactos y sus respectivas fechas de vencimiento.

En definitiva, la Corte Constitucional llega a las siguientes conclusiones:

i) Se consideran derechos adquiridos, aquellos surgidos de las convenciones vigentes antes de la entrada en vigencia del Acto Legislativo 01 de 2005 y a los que tengan acceso a las personas que cumplieron los requisitos para la misma época;

ii) La expectativa legitima de los trabajadores que cumplieron los requisitos durante las prórrogas automática de las convenciones

iii) Es mera expectativa los casos presentado ante la Corte por lo que la misma decide negar el amparo constitucional.

\section{CONCLUSIONES}

1. En cuanto al bloque de constitucionalidad, La Corte Constitucional no tuvo en cuenta la vinculatoriedad de los tratados internacionales, el Estado colombiano dio otra interpretación a las obligaciones internacionales al reconocer que, si bien el Estado está sujeto a estas disposiciones, este mismo puede manejar un rango de interpretación, argumentando así el cambio jurisprudencial en el interés general sobre las legítimas expectativas de los trabajadores que estaban ad portas depensionarse.

En principio, el análisis realizado al Acto Legislativo 01 de 2005 da a entender que esta reforma respeta dichos acuerdos internacionales, así como los principios fundamentales del trabajo, exonerando al Estado de acatar taxativamente los convenios 87, 98, 151 y 154 de la O.I.T. Hace una interpretación acomodada de las recomendaciones del Comité de Libertad Sindical y del Consejo de Administración de la misma entidad. La definición dada a los principios en la sentencia se acomodó a una evidente disparidad en los conceptos de protección de legítimas expectativas.

2. El protocolo de San Salvador, como tratado internacional ratificado por Colombia, obliga al Estado a la protección de derechos adquiridos e impulsa a los suscriptores para que destinen recursos para el avance de los derechos, no solo en calidad sino en cobertura; la interpretación y estudio hecho en Colombia, en cuanto a jurisprudencia respecta, demuestra que el mandato de progresividad no es absoluto cuando se intenta sobreponer al interés general. Esto de acuerdo con la Sentencia C- 251 de 1997, al señalar que los derechos forman una unidad independiente, integral y universal donde no se admite que se desconozca un derecho para salvaguardar otro, sin que se aseguren las condiciones mínimas materiales de existencia.

3. Antes de la Constitución de 1991 la diversificación normativa en pensiones no solventó el principio de cobertura, la inseguridad jurídica permitió masivas situaciones pensionales. Posteriormente, con la nueva Constitución, la fundamentación del derecho de la seguridad social desarrolló el concepto jurisprudencial de protección y cobertura universal, dando prioridad a la sostenibilidad del sistema de seguridad social al aumentar los requisitos para acceder la misma y unificando el sitema por medio de la Ley 100 de 1993.

4. Los principios de favorabilidad y condición más benéfica, constitucionalizados en el artículo 53 , obedecen a una aplicabilidad de la duda en favor del trabajador, la cual debe ser fundada 
y proporcionada para el examen del caso en concreto de una norma en su integralidad. Desde esta óptica la Corte entendió que se debía aplicar el Acto Legislativo 01 de 2005, sin embargo, deja abierta la puerta a diferentes interpretaciones de vigencia y aplicación de la transición normativa de las pensiones convencionales, porque no se optó por la opción más benéfica para los trabajadores, encontrando contradicción en la tradición proteccionista del derecho a la seguridad social.

La interpretación dada por la Corte Constitucional desconoce un desarrollo jurisprudencial entorno a la reglamentación e interpretación del principio de favorabilidad y condición más benéfica, generando la legalidad de una transición normativa que corta ipso facto la causación de derechos. Respecto a ello, la recomendación de la O.I.T se cree suficiente ya que al mantener las convenciones celebradas con anterioridad a la entrada en vigor de la reforma constitucional se protege el pacto celebrado entre trabajadores y empleadores, reconociendo la libertad de voluntades y la falta de denuncia de estos acuerdos, por lo que se debe entender la protección de los plazos estipulados inicialmente.

No se puede dejar de lado que el principio de favorabilidad al igual que la aplicación de la norma en el tiempo pugna respecto a la consideración de lo que se puede tener como derecho adquirido. La norma nueva no puede retrotraer sus efectos para vulnerar situaciones consolidadas como los convenios firmados que reconocen pensiones extralegales. Según la Sentencia C 126 de 1995, el estudio de constitucionalidad sobre el aumento de la edad para poder acceder a la pensión por vejez, de acuerdo a la Ley 100 de 1993, es válido ya que no hay nada pactado con anterioridad en pensiones, que se adquieren conforme a la unificación del sistema en general, contrario a lo que sucedió en el cambio normativo propiciado por la reforma constitucional.

5. La Corte Constitucional reiteró que solo las recomendaciones emitidas por el Comité Sindical, debidamente aprobadas por el Consejo de Administración son vinculantes o de obligatorio cumplimiento para el Estado colombiano, no obstante ello, en la interpretación de las mismas no se determinó una apreciación de compatibilidad con el ordenamiento jurídico. Por ello la adopción de las recomendaciones expedidas por la O.I.T como directrices para la aplicación de los derechos laborales no fueron fuente del alcance del Acto Legislativo 01 de 2005 que creó una limitante interpretación frente a la vinculatoriedad de las recomendaciones de esta corporación internacional.

6. La introducción del principio de sostenibilidad financiera en el ámbito constitucional llevó a la Corte Constitucional a replantear la interpretación del derecho fundamental de la negociación colectiva en el carácter pensional, así como de la seguridad social en general, colocando punto final a las cláusulas pensionales de las convenciones colectivas de trabajo vigentes a la promulgación del Acto Legislativo 01 de 2005.

En cuanto al principio de sostenibilidad no se puede discutir que es indispensable para alcanzar los fines propuestos por el Estado Social de Derecho, esta se debe tener en cuenta como condición para el desarrollo económico en general de todas las ramas del poder público. Para que se dé continuidad a los derechos adquiridos y la cobertura en general de los derechos el Estado debe estar sujeto a perspectivas de vinculación fiscal, racionalizando su cobertura.

7. El acto legislativo no previno un régimen de transición suficiente conforme a las condiciones y beneficios afectados; la proporcionalidad de dicho régimen no tuvo en cuenta una reglamentación de prórroga automática.

Las partes del conflicto se encuentran en capacidad para establecer la conveniencia del pacto de cláusulas presentes a la pensión, en virtud del principio de la libertad de voluntades y en pro del beneficio del trabajador, donde el Estado a través de esta sentencia encuentra el desconocimiento de legítimas expectativas que las empresas no habían denunciado. El pacto en pensiones convencionales no exonera a las personas, mientras tengan vigente contrato de trabajo, según el artículo 17 de la Ley 100 de 1993, de efectuar cotizaciones obligatorias para acceder a la pensión de vejez, de ese modo, como quiera que la ley no consagró disposición en contrario los empleados no pueden exonerarse de esta misma, cumpliendo con la carga fiscal alegada.

8. Al momento de implementar la reforma constitucional, contenida en el Acto Legislativo 01 de 2005, no se prevén normas protectoras 
de expectativas legítimas, en ocasión al capricho del legislador de supeditar este tránsito a una fecha determinada sin tener en cuenta las prórrogas automáticas que se causaran posterior al vencimiento de los acuerdos que nunca fueron denunciados por las partes, pero sí derogados por la restricción normativa constitucionalizada. La intención de proteger las expectativas legitimas no se dio puesto que no se respetaron acuerdos previos a la entrada en vigencia de la reforma constitucional, transformándose esta en una norma retroactiva, de acuerdo a la interpretación de la Corte Constitucional.

Las recomendaciones elevadas por la O.I.T son de vital importancia a una posible solución de este conflicto normativo, puesto que este ente internacional reconoce la necesidad de regresión de derechos en pro de bienestar en general y que la limitación a la negociación colectiva no representa un daño a este derecho, pero sí se debe un razonado y proporcionado régimen de transición en donde muchos trabajadores quedaron en un limbo jurídico respecto de la convenciones donde se reconocían sus derechos y una norma constitucional posterior que no permitió la consolidación de estos mismos, aun estando cerca de obtenerlos. Es por ello que la prórroga de las cláusulas que atienden pensiones convencionales se debe ampliar hasta su primer vencimiento posterior al 31 de julio de 2010, asegurando así el cumplimiento de acuerdos previos y la posterior unificación del sistema pensional, asegurando el principio de sostenibilidad financiera.
9. Frente a la antinomia constitucional entre el parágrafo 2 del artículo 48 y el artículo 93 de la Constitución, la Corte debe establecer una solución a la pugna presentada por estas normas. Como posible solución podría tenerse en cuenta el criterio cronológico, según lo expuesto sobre el principio de sostenibilidad financiera aducido en la sentencia SU-555 de 2014 y la exposición de motivos del Acto Legislativo 1 de 2005, con el fin de dar una mayor seguridad en el ordenamiento jurídico y que no se produzcan interpretaciones contradictorias, al permitir al Estado sobreponer la reforma a las pensiones convencionales. Atendiendo esta situación debe precisarse por parte de la Corte Constitucional la razón que se tiene para prohibir dichas pensiones y para desconocer la libertad de negociación colectiva.

Ahora bien, en caso de dar la solución pertinente por parte de la Corte es claro que la norma antigua perdería los efectos en el ordenamiento jurídico, es decir que si para el caso subsiste la reforma del Acto Legislativo 1 de 2005, quedaría prohibido en el ordenamiento jurídico hacer cualquier negociación frente a pensiones convencionales, es decir que no podrían establecer condiciones extralegales, y se restringiría totalmente la negociación en este sentido limitando así la libertad de negociación colectiva aducida por los convenios de la O.I.T. 


\section{REFERENCIAS BIBLIOGRÁFICAS}

- Arango Olaya. M. (2004). El bloque de constitucionalidad en la jurisprudencia de la Corte Constitucional colombiana. Precedente, 4 (4), 79-102.

- Arenas Monsalve. G. (2011). El derecho colombiano de la seguridad social. Bogotá: Legis Editores S.A.

- Asamblea Nacional Constituyente. (1991). Constitución Política de Colombia 1991. Bogotá: Legis.

- Congreso de la República de Colombia. (1946). Ley 90 del 26 de diciembre de 1946. Por la cual se establece el seguro social obligatorio y se crea el Instituto Colombiano de Seguros Sociales.

- -----. (1993). Ley 100 del 23 de diciembre de 1993. Por la cual se crea el sistema de seguridad social integral y se dictan otras disposiciones.

- -----. (2005). Acto Legislativo 01 del 25 de julio de 2005. Por el cual se adiciona el Artículo 48 de la Constitución Política.

- -----. (2011). Acto Legislativo 3 del 1 de julio de 2011. Por el cual se establece el principio de sostenibilidad fiscal.

- Corte Constitucional. (1999). Sentencia C- 251 de 1997. M. P.: Alejandro Martínez Caballero

- ----. (1999). Sentencia C-481 del 7 de julio de 1999. M. P.: Martínez Caballero. A.

- ---.- (1999a). Sentencia T - 568 del 10 de agosto de 1999. M. P.: Gaviria Díaz. C.

- ------. (2000) Sentencia C- 567 de 2000. M. P.: Alfredo Beltrán Sierra.

- -------. (2001) Sentencia C-579 del 5 de junio de 2001. M. P.: Montealegre Lynett. E.

- ------ (2001a). Sentencia T -559 del 5 de julio de 2001. M. P.: Tafur Galvis.A.

- -----. (2001b) Sentencia C-1287 del 5 de diciembre de 2001. M. P.: Monroy Cabra, M.G.

- ------. (2002). Sentencia C- 789 del 24 de septiembre de 2002. M. P.: Escobar Gil. R.

- -------. (2003). Sentencia C-1056 de 2003.
M. P.: Alfredo Beltrán Sierra

- -----. (2004) Sentencia C-038 del 27 de enero de 2004. M. P.: Montealegre Lynett. E.

- ---.-. (2001) Sentencia C-579 de 2001. M. P.: Montealegre Lynett. E.

- ------. (2005a). Sentencia C-401 del $14 \mathrm{de}$ abril de 2005. M. P.: Cepeda Espinosa, M.J.

- ------. (2010) Sentencia T-488 de 2010. M. P.: Juan Carlos Henao Pérez.

- ------. (2011) Sentencia C-228 del 30 de marzo de 2011. M. P.: Juan Carlos Henao Pérez.

- -------. (2012). Sentencia C-132 del 29 de febrero de 2012. M. P.: Sierra Porto H.A.

- -----. (2013). Sentencia C- C-258 de 2013. M. P.: Jorge Ignacio Pretelt Chaljub.

- ------. (2014). Sentencia SU-555 del 24 de julio de 2014. M. P: Pretelt Chaljub, J.I.

- ------. (2016). Sentencia C-439 del 8 de febrero de 2016. M. P: Guerrero Pérez. L.G.

- Corte Suprema de Justicia. (2012). Radicado 41.695 del 2 de mayo de 2012. M. P. Carlos Ernesto Molina Monsalve

- Cuarto Tribunal Colegiado en Materia Civil del Primer Circuito de México. (2009). Amparo directo 293/2009. 4 de junio de 2009. Ponente: Castillo González. L.

- Guastini, R. (2008). Estudios sobre la Interpretación Jurídica (Octava edición ed.). (M. Gascón, \& M. Carbonell, Trads.) México: Porrúa.

- Jaramillo Campo. K. 2014. Tensión entre el principio de sostenibilidad financiera y el principio de la condición más beneficiosa en la pensión de sobrevivientes. (Tesis de posgrado) Universidad de Antioquia, Colombia.

- Presidencia de la República de Colombia. (1948). Decreto-Ley 2158 del 24 de junio de 1948. Código Procesal del Trabajo y de la Seguridad Social.

- -----. (1950). Decreto 2363 del 5 de agosto de 1950. Código Sustantivo del Trabajo.

- -----. (1968). Decreto 3135 del 26 de 
diciembre de 1968. Por el cual se prevé la integración de la seguridad social entre el sector público y el privado y se regula el régimen prestacional de los empleados públicos y trabajadores oficiales.

- ----. (1971). Decreto 546 del 21 de marzo de 1971. Establece el régimen de seguridad y protección social de los funcionarios y empleados de la Rama Jurisdiccional, del Ministerio Público y de sus familiares.

- -----. (2012). Decreto 1092 del 24 de mayo de 2012. Por el cual se reglamentan los Artículos 7 y 8 de la Ley 411 de 1997 en lo relativo a los procedimientos de negociación y solución de controversias con las organizaciones de empleados públicos.

- Organización internacional del trabajo. Convenio 154 de la O.I.T (1981) Convención sobre la negociación colectiva.

- Uprimny. R. (2005). El bloque de constitucionalidad en Colombia. Red de escuelas sindicales. Recuperado http:// redescuelascsa.com/sitio/repo/DJSBloque Constitucionalidad(Uprimny).pdf.

- Valero Rodríguez. J.H. (2012). Derechos adquiridos en el derecho laboral. Bogotá: Librería ediciones del profesional Ltda. 1ra ed. 